\title{
Transfer of the Cultural Heritage of the Traditional Thai House: Usiri Family Houses
}

\author{
Kundoldibya Panitchpakdi ${ }^{\text {* }}$ \\ ${ }^{1}$ Department of Housing, Faculty of Architecture, Chulalongkorn University, Bangkok 10330, Thailand
}

\begin{abstract}
Traditional Thai house architecture is a significant part the Thai culture and heritage. One unique attribute of traditional Thai house construction is the modular, pre-fabricated wood components, with non-permanent connections. This allows the house to be dissembled and reassembled in a new location without damage. This is a case study of Thai-style houses built and owned by six generations of the Usiri family. Their houses have been passed down from the first to subsequent generations. From only two Thai-style houses 130 years ago, there are now eleven houses as part of an expanding cultural inheritance.
\end{abstract}

(C) 2016. The Authors. Published for AMER ABRA by e-International Publishing House, Ltd., UK. This is an open access article under the CC BY-NC-ND license (http://creativecommons.org/licenses/by-nc-nd/4.0/).

Peer-review under responsibility of AMER (Association of Malaysian Environment-Behaviour Researchers), ABRA (Association of Behavioural Researchers on Asians) and CE-Bs (Centre for Environment-Behaviour Studies), Faculty of Architecture, Planning \& Surveying, Universiti Teknologi MARA, Malaysia.

Keywords: Cultural Heritage; Traditional House; Preservation; Living Environment.

\section{Introduction}

Samut Songkhram lies just outside of Bangkok and has the smallest area in the country. The terrain is flat and low-lying and borders on the Gulf of Thailand. It has many features of historical significance and an abundance of natural resources.(Kirdsiri \& Suedee, 2010: 30). The province has pursued sustainable development to achieve a balance between economic advancement, socio-cultural pursuits, and the environment. It ranks first in the nation for human security (Panitchpakdi, 2009) and is well-known for its agriculture and eco-tourism attractions

In 2009, a research study was conducted on participatory housing development planning in Samut Songkhram. Community residents and development partners developed an action plan for the regeneration of traditional Thai

\footnotetext{
${ }^{*}$ Kundoldibya Panitchpakdi. Tel.: +662 2184355

E-mail address: kpanitchpakdi@gmail.com
}

2398-4287 @ 2016. The Authors. Published for AMER ABRA by e-International Publishing House, Ltd., UK. This is an open access article under the CC BY-NC-ND license (http://creativecommons.org/licenses/by-nc-nd/4.0/).

Peer-review under responsibility of AMER (Association of Malaysian Environment-Behaviour Researchers), ABRA (Association of Behavioural Researchers on Asians) and cE-Bs (Centre for Environment-Behaviour Studies), Faculty of Architecture, Planning \& Surveying, Universiti Teknologi MARA, Malaysia.

DOI: http://dx.doi.org/10.21834/e-bpj.v1i3.368 
dwellings with cultural heritage significance (Panitchpakdi, 2013). A collaborative survey of communities found that there were more than 300 domiciles that exemplified the features of the traditional Thai house in the study area (Kirdsiri \& Suedee, 2010: 47). Half of these houses were in satisfactory condition while the other half were in various states of disrepair. If they are left to degenerate, then this heritage and tourist attraction will gradually go extinct. In 2012, a provincial committee was appointed to address the preservation of Thai houses and develop a local curriculum on Thai traditional housing (Panitchpakdi, 2015).

Throughout the five-year process of collaboration learning, Chaiyan Usiri, former Chairman of the Samut Songkhram Chamber of Commerce, consistently contributed to the research activity.This shows that Chaiyan genuinely loves traditional Thai-style houses and has dedicated himself to their preservation. Chaiyan has proposed that his own, adapted Thai house cluster be used as a Thai Traditional House Learning Center. The first cluster houses Usiri's family is over 100 years old and have been passed down through the generations. It is instructive to understand the process of repeated transfer of these houses from parent to child, and what were the facilitating factors which led to this heritage that extends to the present day. That knowledge could inform guidelines for others who wish to see the continued preservation of the traditional Thai-style house in the years ahead.

\section{Objectives}

1) To study the physical characteristics and components of the Thai traditional cluster houses in different generations of the Usiri family;

2) To study the household characteristics, and living culture of the various generations of the Usiri family;

3) To analyze the cultural heritage transfer from one generation to the next through the medium of the traditional Thai-style house and factors of success.

\section{Review of the Literature}

\subsection{Cultural Heritage Transfer}

Cultural arises out of lifestyle activities which a group of humans creates together and pass on to subsequent generations as a blueprint for replication. Culture is not instinctive or static; it is a learning and living process which evolves over time, becoming a part of the social heritage. As society modernizes, new features are absorbed by the culture to conform to the evolving environment. Thai culture has certain norms about dressing, eating, and living which has been passed down through the generations, and are distinct from other cultures (Center for Culture and the Arts, Burapha University, 2010). The traditional Thai house is one of these unique features and remains an important part of the cultural heritage of the Thai people (Pinkanngern, 1969).

The main categories of heritage are (1) Tangible cultural heritage: and (2) Intangible cultural heritage (UNESCO, 2016a) which refers to the practices, representations, expressions, knowledge and skills handed down from generation to generation. Intangible cultural heritage is also known as "living heritage" or "living culture" (UNESCO, 2016b). Cultural heritage is manifested: (1) Oral traditions and expressions (2) Performing Arts (3) Social practices (4) Knowledge and practices concerning nature and the universe (5) Traditional craftsmanship

\subsection{The traditional house of central Thailand}

The traditional house of central Thailand represents a unique architectural structure. The design has evolved over a long time, dating from the Ayutthaya Era (14th-18th C.) (Tongsarote \& Paninth, 2012) and was influenced by the prevailing outlook on life, Buddhist beliefs, topography and climate, and agrarian lifestyle (Tongsarote \& Paninth, 2014). The result is a house tailored to the daily needs of simple living and that provides protection from direct sunlight, rain, flooding, and heat (Malakul, 1986: 5). The construction methods draw upon locally-available resources, and reflects conservative customs and wisdom, as passed down through many generations. 
Key features of the traditional Thai house include the living area being raised on stilts (Silapacharanan, 2013: 31), a high ceiling, lengthy eaves, and ample porch/veranda area (Malakul, 1986: 22). The house is multi-purpose and has sparse furniture. The principal construction material is wood assembled into modules. Each module is fully constructed before assembled with the other components (Pirom, 1995). Components of the house can be dis- and re-assembled at another location. (Pirom, 2002).

Modules, construction, and dis-assembly of the traditional Thai house

The traditional Thai house has five main components: Foundation and house posts; (2) Structure for supporting the main floor and roof; (3) Roof structure; (4) floor and (5) Walls, doors, windows, and stairs. It is noteworthy that all of these components are made out of wood (Kosate, 25-50, referenced in Tongsarote \& Paninth, 2012). See Fig. 1.

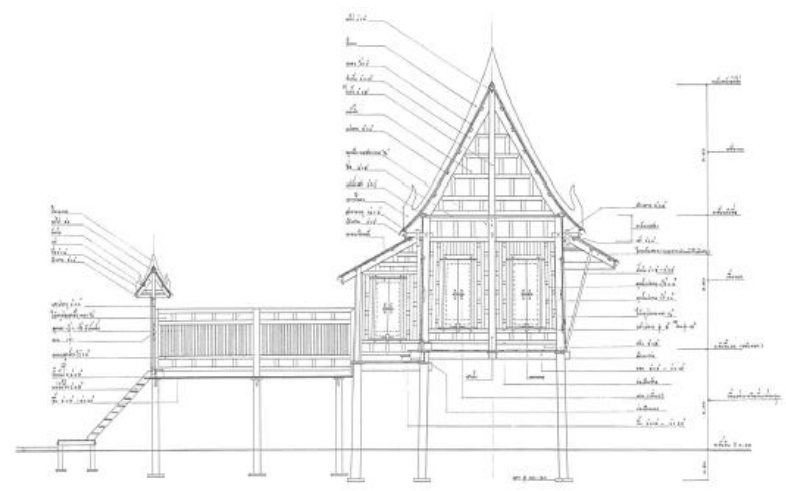

Fig. 1: Cross-section of Traditional Thai House

A variety of wall panel designs includes the Fa Pakon (composite wall paneling); Fa Saibua (vertical paneling), Fa Samruat (wood-and-bamboo paneling), Fa Thang (removable plank wall) (Reuthai Jaijongrak, 1996: 170) (Fig. 2). Different styles of gable panel (Na Chua) include Luk Fak Na Phrom (stepped design), Bai Prue (horizontal siding), and Phra Athit (sunburst) (Jaijongrak, 1996: 183; Kirdsiri \& Suedee, 2010: 48) (Fig. 3).
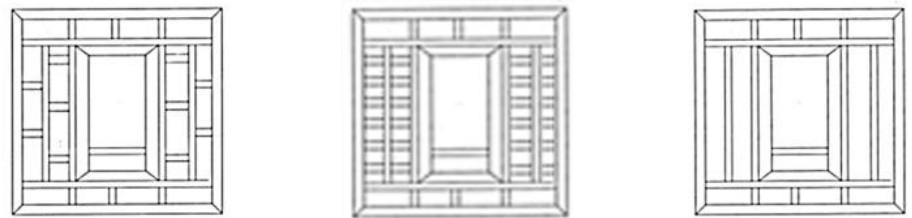

Fig. 2: Some Types of Wall Panels in Traditional Thai House: (a) Fa Pakon (b) Fa Samruat (c) Fa Saibua
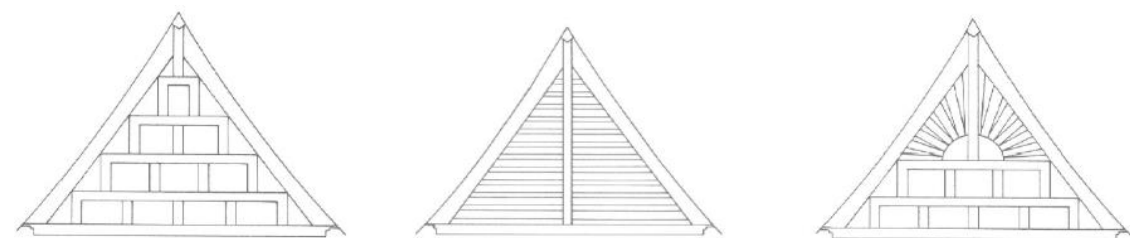

Fig. 3: Gable Panels of the Traditional Thai House: (a) Luk Fak Na Phrom (b) Bai Prue (c) Phra Athit (Kirdsiri \& Suedee, 2010: 49)

\subsection{Transmission of the Value of Thai Traditional House}

Thai architectural identity of Thai house revealed two characteristics; (1) Tangible identity corresponds to the location, weather, discoverable natural resource which occurrences included risen Thai house with delicate gable which made by wood as the main material and pillars which incline to each other. The body of the house can do 
disassembly. (2) Intangible identity appeared from the sense of living, using and touching. The building of Thai house related to religion and belief of auspicious occasion. The value of architectural identity of Thai house can be identified to (1) the benefit of usage the house, the aesthetic value, the value of mental engagement of resident, the value of merit for the resident. (2) Values of the society included the value of Buddhism, the value of family engagement and the harmoniousness in the community. (3) Value to the Nation: Thai house is the heritage of Thai wisdom and the country's sustainable development.

Transmission guidelines of value of Thai architectural identity: 1) Emphasizing the importance and value of Thai house identity 2) Cultivating the conscious mind in knowledge conservation 3) Applying the former knowledge to the current 4) Cultivating the behavior of perseverance 5) Relaying the knowledge through the family, school as well as the government sectors 6 ) The promotion of activities with the network establishment and knowledge distribution to the community 7) The integration of community-based learning 8) Building on to access the creative economy and 9) Propagating the value of Thai architectural identity through media. (Chitrojanarak, 2014)

\section{Methodology}

This research applied the purposive selection of 4 Thai traditional cluster houses of the Usiri clan as a case study. The research methodology comprises of (1) Reviewed related literature, (2) Survey and assessment of the physical characteristics and components of four clusters of Thai traditional houses built over two generations; (3) Indepth interviews with five household members of Usiri clan from the fourth generation (Gen4) and the Gen5 of descendants and also interviewed one construction artisan who single-handedly built these cluster houses.

\section{Findings}

\subsection{The Usiri Clan}

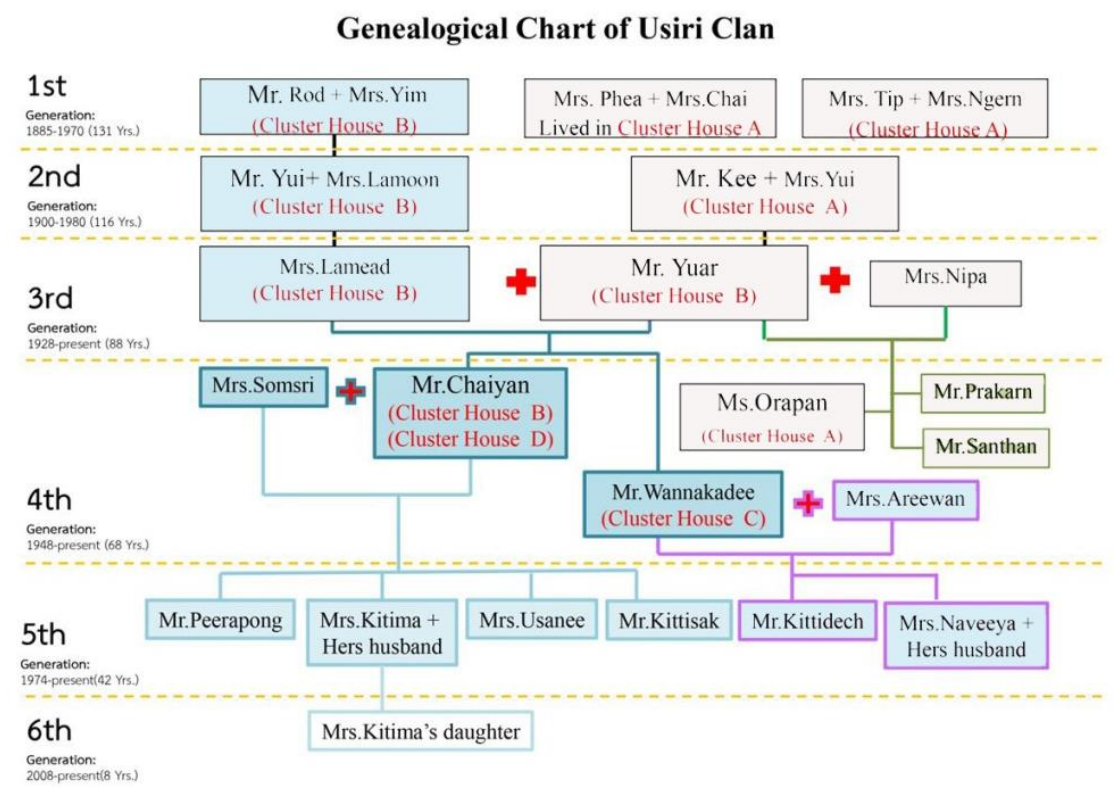

Fig. 4: Genealogical Chart of Usiri Clan

The Usiri family has preserved their Thai houses through inter-generational inheritance. The family first settled in Samut Songkhram in 1885, and currently spans six generations or over 131 years (Usiri, C. \& Usiri, O., Interview, 
December 14, 2015; Usiri, W., Interview, January 29, 2016; Usiri, K., Interview, February 4, 2016; Usiri, N., Interview, Fenruary 11, 2016). Two houses built by the first generation transfer to be four clusters of dwellings, occupied by members of Gen4 (Fig. 4).

\subsection{Characteristics of the Usiri Houses and Household Characteristics}

\section{(1) House Cluster A}

The first houses in this cluster were built by Gen1 over 130 years ago. The Characteristics of the original house are unknown. Chaiyan remembers this complex when he was ten years old. At that time, the house cluster was 63 years old. Chaiyan's paternal grandfather (Gen2) erected four houses, raised 1.5 meters off the ground. House A\#1 was a five-room kitchen-house. House A\#2 is the main three-room house included of the grandfather's bedroom and a Buddhist prayer room. House A\#3 also a three-rooms house, including the bedroom of Chaiyan's father. House A\#4 is a multi-purpose living area. The total area of the cluster is 267 sq.m., of the multipurpose common space $78 \%$ and Private space $22 \%$.

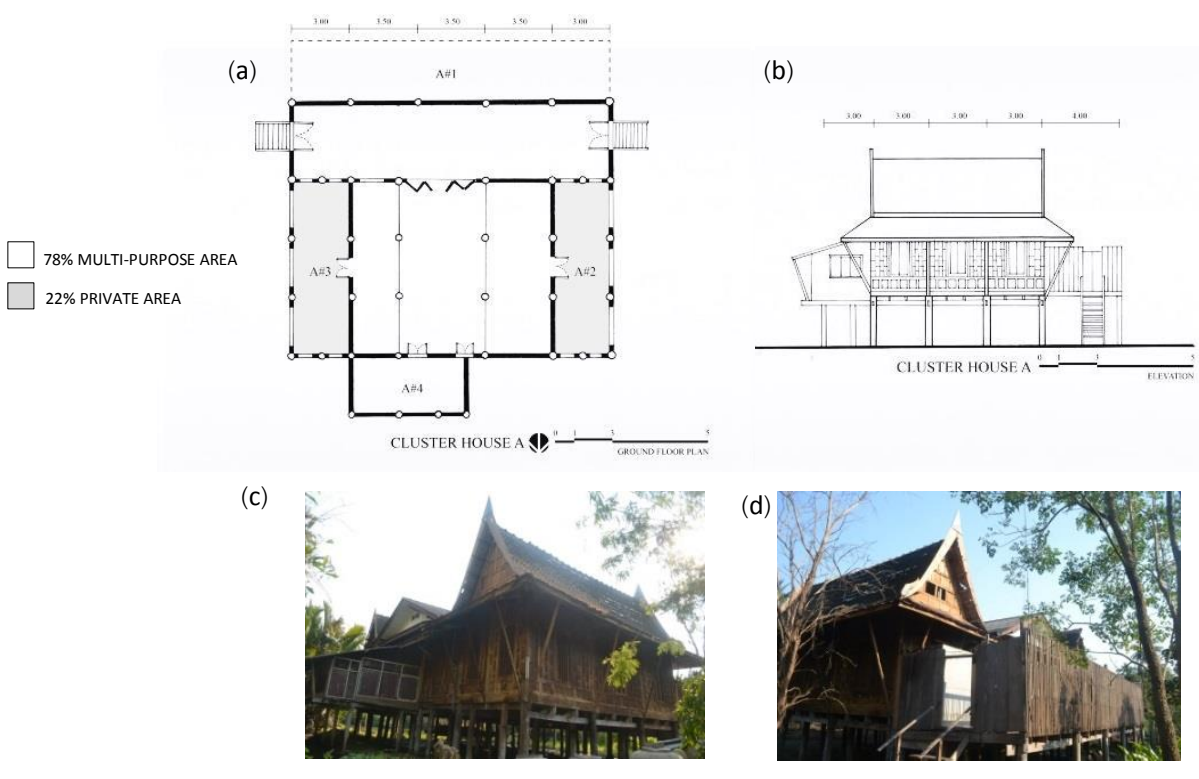

Fig. 5: House Cluster A (a) Second Floor Plan (b) Elevation (c) House A\#2 (d) House A\#2

\section{Household characteristics}

The Gen2 occupants initially included nine family members: Chaiyan's paternal grandparents, Chaiyan's parents (Gen3), and the Gen4 children. The primary family occupation is managing a large orchard farm. The family also produces coconut-sugar. All the adults in the family work in the orchard and all have skill in making home repairs. The grandfather sleeps in House $\mathrm{A \#}_{2}$ while the grandmother, mother and Gen4 children sleep in the multi-purpose living area.

\section{Heritage Transmission}

After Chaiyan's grandfather had died, the ownership was transferred to Chaiyan's father and remained that way until 1985, when he moved to Bangkok. The houses in the cluster were then bequeathed to Gen4 members as 
follows: HouseA\#1 to Chaiyan; and the remaining houses and land to Oraphan. After assuming ownership, Oraphan began to refurbish the houses. At present, Oraphan stays in this house from time to time. The general condition inside of the houses is livable. However, there is an immense degradation of the veranda. Oraphan has no intention of selling her houses and will continue to refurbish them (Usiri, C. \& Usiri, O., Interview, December 14, 2015).

\section{(2) House Cluster B:}

Members of Gen1 on Chaiyan's ancestral maternal side created this cluster in 1892. The original of cluster B has only a three-room house (B\#1), including a bedroom and prayer room. There was a single porch in front of the house, facing the canal waterway. The main floor was raised just high enough to avoid flooding. About 100 years ago, Chaiyan's maternal grandparents (Gen2) expanded the compound by building four new tree-room houses. House $B \# 2$ is a twin to House B\#1 and is use as a multipurpose area. House B\#3 is an area for receiving guests. House B\#4 serves as a kitchen, and the grandmother's bedroom (Usiri, C. \& Oy, Interview, January 27, 2016) Total area of the cluster is 444 sq.m., of the multipurpose common area $80 \%$ and Private area $20 \%$.

\section{Household Characteristics}

In 1958, when Chaiyan was ten years old, he moved from House cluster A to House cluster B. At that time, House Cluster B had five occupants: the maternal grandparents, Chaiyan and his mother, and Wannakadee (a younger sibling). The primary family occupation is orchard gardening. The (maternal) grandmother is very frugal and hard-working, and this has contributed to the good economic standing of the household. Thus, the family has been able to continually expand the size of the orchard. The grandmother instills values of industriousness in the members of the younger generation and makes sure that each one has the relevant life skills to manage the household. The focus is on sufficiency economy and simple living, love of the garden and nature at-large.

\section{Living arrangements in the household:}

The grandfather slept in the main house (B\#1), the grandmother slept in front of the kitchen (B\#4), while the other three slept in the multi-purpose room (B\#2). The veranda and shared space serve as a place for work, relaxation, meals, and educating Chaiyan and Wannakadee about household chores and gardening. Family elderly indoctrinated the two youth about the traditional customs, culture, and practices.

\section{Heritage transmission}

In 1985, when Chaiyan assumed ownership of House A\#1 (ClusterA) from his father (Gen3), he decided to regenerate house cluster $B$ by raising the floor of the cluster to above head-height. He transferred some of the panel modules of House A\#1 to House B\#2 and B\#3 and kept some panel modules.

In 1987, Chaiyan observed the skill of the construction artisan name Oy, and commissioned him to remodel House cluster B. Later, in 2004, Chaiyan moved the kitchen from House Cluster B to a separate facility building. A bedroom was created on the ground floor of House Cluster $B$ for his mother.

Chaiyan married in 1972 and had two sons and two daughters. The family lived in this traditional Thai housing cluster B until the children reached adolescence and moved to Bangkok to school and working opportunities. In 2004, Chaiyan was building the Ban Dara Resort in the area of House Cluster B and asked his daughter (Kittima) to live and work there. Thus, at present, this cluster has five occupants: Chaiyan's mother (Gen3), Chaiyan (Gen4), Kittima and her husband (Gen5), and their son (Gen6). Kittima and her immediate family occupied the main house B\#1. Chaiyan stays with and looks after his mother on the ground floor of B\#4. The lower level under B\#1 and B\#2 is now a multi-purpose area and storage. 
(a)

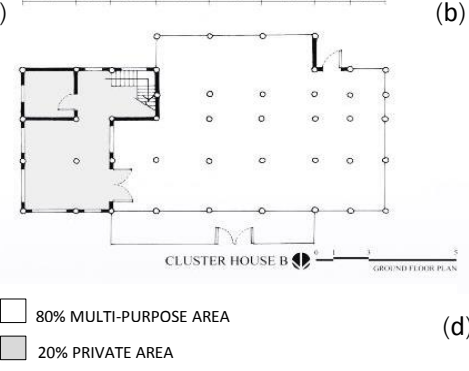

(b)

(d)
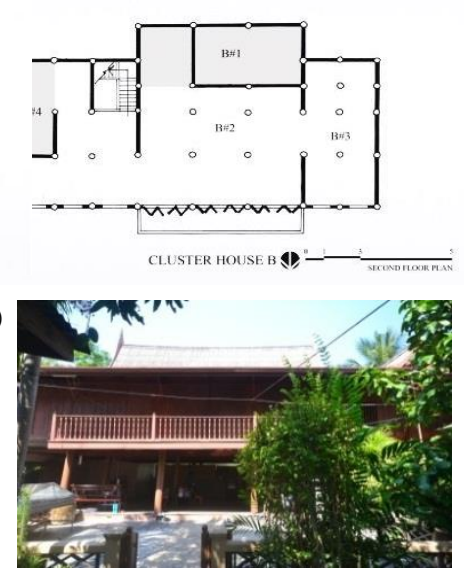

(c)

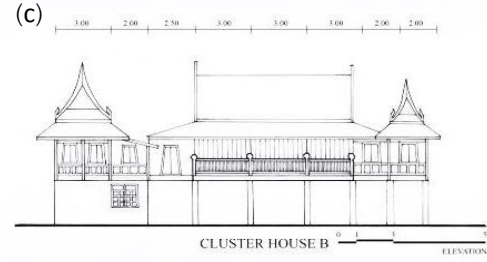

(e)

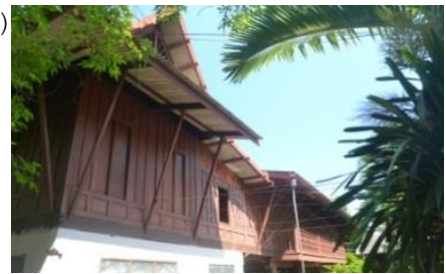

Fig. 6: House Cluster B (a) First Floor plan (b) Second Floor Plan (c) Elevation (b) House B\#2(e)House B\#4

Even Gen 5 of the family has more private quarters; they still meet as a group in the multi-purpose area. It is customary for families living in three-generation compounds. Chaiyan intends to offer the House Cluster B as a heritage to his children and grandchildren and, thus, was determined to use a highest-skilled artisan to help preserve the unique features of the house.

\section{(3) House Cluster C:}

(A 22-year-old Cluster Houses of Wannakadee in Pathum Thani were built in 1994.)

Wannakadee first lived in Cluster House A (in Gen2 era) and then moved as a child to live in House Cluster B when his maternal grandparents (Gen2) were still the owners. He lived with Chaiyan and their mother until he was a teenager then he moved to Bangkok to continue their education and pursue employment opportunities. Wannakadee married in 1978. In 1987, he visited Cluster House B and was impressed with the artisanship of Oy, who was in the process of refurbishing the property. This inspired Wannakadee to build Cluster House $\mathrm{C}$ as a master demonstration piece of the artist construction skills of Oy. Chaiyan agreed to bequeath the components of House A\#1 from his first generation to his younger brother for adaptation to Cluster House $\mathrm{C}$, to be built in Pathum Thani starting in 1994 (Usiri, W., Interview, January 29, 2016).

The construction took eight years (1994-2002), and Artisan Oy crafted all new wooden components alone. The cluster has five Thai-style traditional wood houses placed on the second floor on top of a ground floor built of reinforced concrete. The first floor is divided into a guest area, dining area, and a kitchen in a modern house style. Centrally-located stairs lead to the second floor, which differs from the traditional Thai design, as for security reasons.

In the second (Thai-style) floor of House Cluster C, the C\#1 is a three-room house where Wannakadee and his wife reside. It is his inheritance from A\#1 house of his paternal grandfather (Gen1). Oy reassembled and made some adaptations, but these were quite intricate and were the last to be completed in the cluster. House C\#2 also a three-room house, and is occupied by Wannakadee's daughter (Naweeya) and her husband (Gen5). House C\#3 is a two-room house and is periodically resided by Wannakadee's son (Kittidate, Gen5). House C\#4 is a two-room house and serves as a guest house. In addition to these four houses, there is a Thai-style pavilion which serves as a multi-purpose area for the whole family activities. The total area of the cluster is 774 sq.m., of the multipurpose common area $62 \%$ and Private area $38 \%$. 
(a

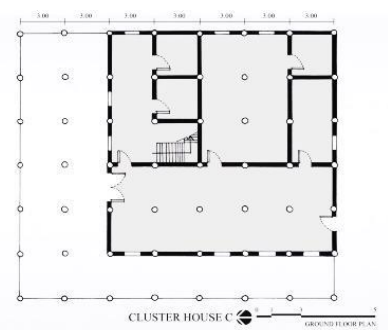

(b

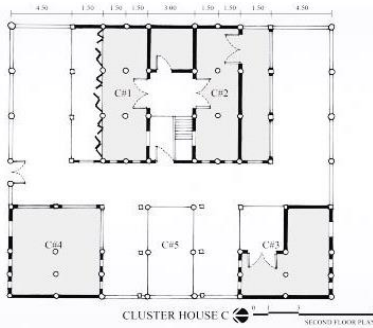

(c)

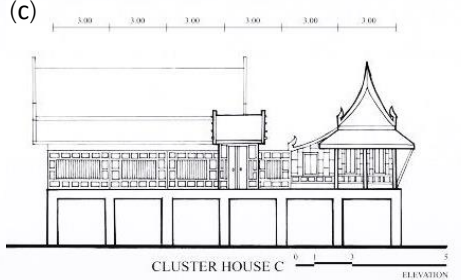

62\% MULTI-PURPOSE AREA

$38 \%$ PRIVATE AREA
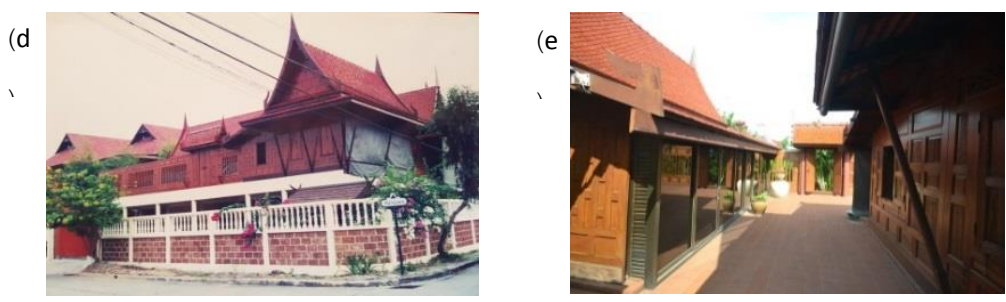

Fig. 7: House Cluster C (a) Ground Floor Plan (b) Second floor plan (c) Elevation (d) House C\#4 (e) House C\#4(left) and C\#1(Right)

Thus, this House Cluster $C$ is a combination of the modern with the traditional styles, honoring both the nuclear and extended family traditions. However, this Thai-style house may be less multi-purpose spacious than in the past because of the preference for separate bedrooms, but still more multi-purpose area when compared to modern houses constructed in the same period. However, it is noteworthy how this hybrid construction accommodates the styles and preferences of different generations in the same family. In the future, this Cluster House $C$ planned to be inherited by the daughter (Gen5) who is soon to have a child (Gen6). Naweeya and her husband plan to preserve this Thai tradition house cluster since they highly value the traditional architecture.

\section{(4) House Cluster D:}

A Learning Center of Traditional Thai Houses and Culture, Suan Luang, Samut Songkhram. Construction of this center began in 2010 and still ongoing. The center was the idea of Chaiyan to inspire a greater appreciation of the Thai cultural heritage. The target audience is the younger generation to give them hands-on experience and knowledge, by allowing a home-stay activity. This center has four houses. House D\# 1 was built in 2010 is a threeroom traditional Thai house raised 3.0 meters above ground floor on a foundation of reinforced concrete. House D\#2 was built in 2012 and includes a shared bathroom. It only has one level and is a hybrid between traditional and modern Thai styles. House D\#3 is a three-room Thai traditional house. It was built in 2013 on a foundation of reinforced concrete. Construction on House D\#4 began in 2014 and currently near completion. This house is a blend of the traditional Thai construction with an application of modern architecture. The foundation is reinforced concrete, and some walls are made of brick with plaster finishing in the design resembling features of the traditional Thai wooden walls. The roofs are made of wood but are not highly sloped as the traditional ones. There is a multipurpose room for conference and exhibition.

This House Cluster $\mathrm{D}$ shows how the traditional and modern can be combined in an artful and practical way. The success of this hybrid design can serve as a living and learning center. Chaiyan (Gen4) and Oy have incorporated unique features of traditional Thai houses in a harmonious blend of modern technology and 
architecture. These houses will be attractive to the new generation as well as their parents who have fond memories of the warmth, sharing, and togetherness of the traditional, Thai-style housing compound.
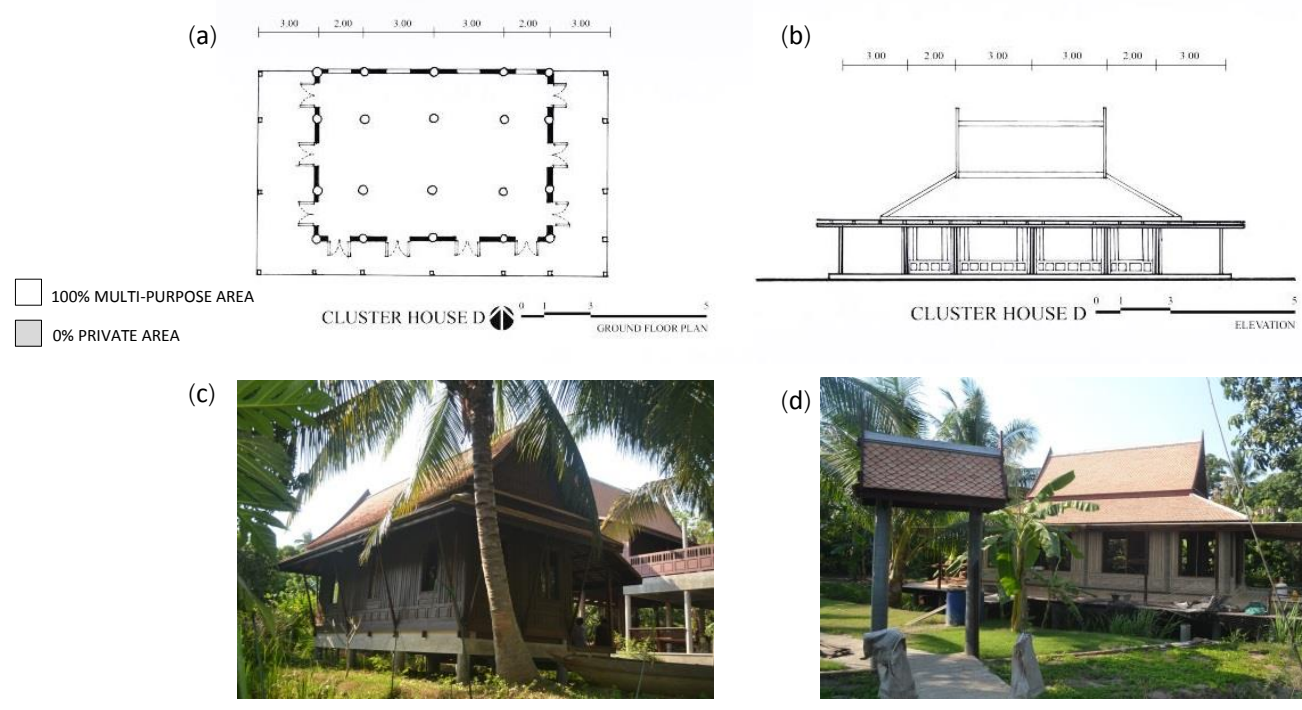

Fig. 8: Cluster House D (a) Plan (b) Elevation (c) House D\#3 (b) House D\#4

\section{Transfer of Cultural Heritage}

\subsection{Tangible Cultural Heritage}

(1) Transfer of tangible elements of the traditional Thai house heritage:

This study found that a unique attribute of Thai-style houses is that the components are modular and can be passed down piecemeal or as a unit to descendants. This study documented the transfer of a 130-year-old house by a Gen1 owner to his children and grandchildren who expanded 2 of Gen 1 house clusters into 3 clusters with eleven houses in Gen 4;

(2) Transfer of the aesthetics of Architecture of the traditional Thai house:

The transfer of components of original house of Gen1 helped to preserve the style of housing design and the unique, artistic features to the Gen4 descendants. This process serves as both a display and guideline of how Thaistyle houses were built and appeared in antiquity. In this way, artifacts of the culture over a century ago are preserved in living and learning way. 


\subsection{Intangible Cultural Heritage}

\section{(1) Transfer of living behavior culture:}

This study found that the three persons most responsible for passing on the clan's houses were born in the homestead, and lived together with more than two generations. This preserves the traditional extended family household, with shared meals, recreation, and housework. Each had the same indoctrination by their elders, both verbally and in practice. The three respondents cited key attributes that were passed on through the generations, including frugality, industriousness, courteousness, simple living, working in harmony with others in the common multipurpose area of the household rather than alone. Each learned how to repair and maintain components of the household and orchard themselves. The children and grandchildren are all involved in this sharing so that they absorb the historical culture and pass it on to their descendants. These features reflect an intangible heritage through oral traditions and expressions as recognized by UNESCO (2016b).

\section{(2) Transfer of a sense of the value of the traditional Thai house and living in a Thai-style manner:}

The Gen4 members thoroughly recognize the value of the artful nature and unique features of the Thai-style house. Also, they recognize the value of living in a Thai-style manner, for example, by sharing chores with each other in the multi-purpose common area, rather the being alone. Even through the owners have made some modifications to accommodate modern preferences, they have always preserved the essential features that make the house uniquely Thai. What is more, they made sure to use the most gifted artisan to do the entire construction of each new house, even though this required considerably more time for construction. In this way, each house is a form of a sculpture by a single artisan - and this is truly unique in the modern world today.

\section{(3) Transfer of traditional craftsmanship:}

Oy is the craftsman who single-handedly built the houses in 3 clusters of Gen 4 . He has worked continuously with the Usiri clan for over 29 years and is considered to be a relative of the family. He learned the craft of homebuilding by disassembling and re-assembling old Thai-style houses. Over the years, he has integrated some modern technology to facilitate the process. He also attempts to use every piece of lumbar, without excess. Oy has very high skilled that his work is truly seamless construction which is hard to see where one piece of wood ends and the other begins. Oy is truly a one-man master builder. He uses his ingenuity to construct these large houses which require creative thinking such as how to erect of heavy pilings all by him-self. Because of his high craftsmanship, Oy is recognized as a "local guru" and repository of traditional wisdom. Each cluster house took over five years to complete and each may consider being a unique art sculpture.

The passing on of this traditional wisdom of this case embodies four out of the five criteria for transfer of the intangible heritage as recognized by UNESCO (2016a).

\subsection{Factors in the success of this cultural transfer}

Factors in the success of this cultural transfer through time is that the Gen4 members were (1) born and lived in the traditional Thai house of their parents and grandparents from infancy until adolescence. That gave them enough time to deeply absorb the quality lifestyle that is facilitated by a Thai-style house and the happiness that results. This has instilled love and motivation to preserve the traditional Thai house; (2) Having an adequate financial ability to preserve the Thai-style house. The new generations absorb the attributes of being hard-working and frugal that were passed down through the generations has contributed to the clan members' financial stability. In this way, Gen 4 of the Usiri family clan was able to save considerable funds to help maintain and expand the houses as a form of cultural preservation for posterity. Overall, this construction effort was costly and consumed many years and something that most families in the locality probably cannot afford. 


\section{Recommendations for preservation of the Thai-style houses}

1. There should inter-generational transmission of both the tangible and intangible heritage of the Thai-style house as part of the cultural heritage of the nation. This can be accomplished by adapting the traditional wisdom to modern needs and trends (Chitrojanarak, 2014). (1) 'Tangible' refers to (a) Having the architectural style that conforms to the topography and climate of the locale, being comfortable for living and energy efficient; (b) Having a common area for family activities instead of living individually; and (c) Using renewable sources of wood, that are shaped into modules for new adaptations. (2) 'Intangible' refers to (a) living frugally and simply, with the transfer of the culture in the process of living together as an extended family with joint activities, (b) with support for artisans and skills which are currently in short supply.

2. There should be urgent efforts to transfer the traditional wisdom because when the Gen who was born into today's household (Gen 4) are passed away, then the chain of transmission for preservation of the culture will be near impossible.

3. To effectively transfer the heritage, there is a need to share the knowledge and love of the Thai-style house in all aspects and at the level of the family. This research found that the family institutions is the most important factor in the transmission process, in addition to the school and administration at all levels, formal and community-based, and extending into the creative economy (Chitrojanarak, 2014).

The knowledge gained from this research will be applied to local curricula for training in the preservation of the traditional Thai-style house that is currently in use. The local community-based training curriculum is expected to expand the level of activity and community learning so that the local administrative organizations produce plans and budgets to help conserve Thai-style houses in the years ahead.

\section{References}

Chirawet, S. (2005). Khon Maeklong (6 $6^{\text {th }}$ ed.). Bangkok: S. Asia Press (1989).

Chitrojanarak, A. (2014). Transmission Guidelines of the Value of Thai Architectural Identity: Faculty of Education, Chulalongkorn University.

Center for Culture and the Arts, Burapha University. (2010). Thai cultures and norms: The overlook beauty. Retrieved from, https://thaiculturebuu.wordpress.com/ $\% / 06 / 07 / 2010 \mathrm{E} \% 0 \mathrm{~B} \% 8 \mathrm{~A} \% 5 \mathrm{E} \% 0 \mathrm{~B} \% 8 \mathrm{~B} \% 1 \mathrm{E} \% 0 \mathrm{~B} \% 81 \% 8 \mathrm{E} \% 0 \mathrm{~B} \% 8 \mathrm{~A} \% 9 \mathrm{E} \% 0 \mathrm{~B} \% 93 \% 8 \mathrm{E} \% 0 \mathrm{~B} \% 8 \mathrm{~B} \% 0 \mathrm{E}$ $\% 0 \mathrm{~B} \% 82 \% 8 \mathrm{E} \% 0 \mathrm{~B} \% 8 \mathrm{AD} \% \mathrm{E} \% 0 \mathrm{~B} \% 87 \% 8 \mathrm{E} \% 0 \mathrm{~B} \% 8 \mathrm{~A} \% 7 \mathrm{E} \% 0 \mathrm{~B} \% 8 \mathrm{~B} \% 1 \mathrm{E} \% 0 \mathrm{~B} \% 92 \% 8 \mathrm{E} \% 0 \mathrm{~B} \% 99 \% 8 \mathrm{E} \% 0 \mathrm{~B} \% 98 \% 8 \mathrm{E} \% 0 \mathrm{~B} \% 8 \mathrm{~A} \% 3 \mathrm{E} \% 0 \mathrm{~B} \% 8$ $\mathrm{A} \% 3 \mathrm{E} \% 0 \mathrm{~B} \% 8 \mathrm{~A} / 1$

Jaijongrak, R. (1996). Traditional Thai Houses. Bangkok: The Association of Siamese Architects under Royal Patronage.

Kirdsiri, K. \& Suedee, K. (Eds). (2010). The Map of precious cultural and environmental communities in the Samut Songkhram.Bangkok: Faculty of Architecture, Silapakorn University.

Panitchpakdi, K. ( 2009). Changes of housing in Samut Songkhram. In Tapananont, N.(Ed.), Symposium on Thai Houses and Cultural. Bangkok: Faculty of Architecture, Chulalongkorn University.

Panitchpakdi, K. (2013). Housing Development Plan: Samut Songkhram. Bangkok: Chula Unisearch, Unulalongkorn University.

Panitchpakdi, K. (2015). The progress report of research in an architecture for community empowerment. Bangkok: Faculty of Architecture, Chulalongkorn University.

Pinkanngern, W. (1969). Thai Fine Arts and craftsmanship and heritage site. Bangkok: Odeanstore.

Malakul, P. (1986). Evolution of Central Thai Houses. Bangkok: Faculty of Architecture Chulalongkorn University.

Tongsarote, P. \& Paninth, O. ( 2012). Changes of forms and elements of the central Thai traditional house in the present day. Faculty of Architecture Academic Journal, KMITL, 16(18), 35 - 48.

Tongsarote, P. \& Paninth, O. (2014). A study of how to find and create the proportion of additional central Thai traditional houses from standard proportion based on Associate Professor Rutai Jaijongruk. Journal of Industrial Education, 13(2), 
Silapacharanan, S. (2013). The identity of water-based communities in Thailand. Procedia - Social and Behavioral Sciences, 85(20 September 2013), $27-32$.

Pirom, S. (1995). Thai Houses. Bangkok: Asset management.

Pirom, S. (4th Ed.). (2002). Thai houses in Central of Thailand. Bangkok: Suksapan.

UNESCO. (2016a). What is meant by "Cultural Heritage"?. Retrieved from, http://www.unesco.org/new/en/culture/themes/illicit-trafficking-ofcultural-property/unesco-database-of-national-cultural-heritage-laws/frequently-asked-questions/definition-of-the-cultural-heritage/

UNESCO. (2016b). Safeguarding Communities' Living Heritage. Retrieved from, http://www.unesco.org/new/en/culture/resources/in-focusarticles/safeguarding-communities-living-heritage/

Usiri, C. \& Usiri, O. 2015, December 14. House owners cluster B \& D. Interview.

Usiri, C. \& Oy. 2016, January 27. House owner and artisan. Interview.

Usiri, W. 2016, January 29. House owner cluster C. Interview.

Usiri, K. 2016, February 4. House owner cluster B. Interview. 